\title{
Identity Theory and Conflict
}

\author{
Rodolfo Montecinos Ohlagaray* \\ Lawyer , Master ${ }^{\oplus}$ en Resolución de Conflictos y Mediación, Universidad Europea del Atlántico (Spain), Chile
}

*Corresponding author: Lawyer , Master ${ }^{\complement}$ en Resolución de Conflictos y Mediación, Universidad Europea del Atlántico (Spain), Chile

\section{Perspective}

The times we are currently living in are very difficult, sometimes very complex to understand from a sociological point of view. Society is a fuzzy concept, complex, sometimes, not very predictable. The combination of deficiencies in decision-making in the current scenarios, reflects the little knowledge on the subject to be dealt with, these groups, particularly vulnerable to initiate or sustain over time projects that come to contain regrettable and inefficient policies. There are many known interactions between the identity trilogy (in its individual and group manifestations), and its related psychological concept of self-esteem, and conflict.

One of the most stable findings in the field of conflict transformation is the direct relationship between the negative trilogy of what was previously exposed, thus, poorly established identities, low self-esteem and destructive conflicts; conversely, in their relationship, well-established identities, high self-esteem, and few destructive or cooperative conflicts.

Social identity is a concept referring to the social use of cultural markers to claim, achieve or attribute group membership. This definition points to different dimensions of what is sometimes known as political identity. Sometimes these battles escalate into mutually destructive conflicts. In these circumstances, loyalty to identity groups becomes the ultimate value. These identity groups, for some may be nationalism, ethnicity, for others race, religion for some believers, sexual orientation, sports team, etc.

In most of the most recalcitrant, deep-rooted, fundamental conflicts, they occur between identity groups. Much popular knowledge and academic work is based on this fact. Terms such as ethnocentrism, prejudice, stereotype, xenophobia, racism, suggest the existence of a broad descriptive apparatus of the role that social identity plays in the conflict. A casual look at the dramatic conflicts that appear in the daily press reveals the powerful explanatory power that the mass media assigns to these identity- related phenomena. Furthermore, the identity factor is so powerful that, once invoked, it turns off or cancels any other analysis and even curiosity about these phenomena. This is true, regardless of ethnicity, religion, nationality (or in its extreme nationalism), or any of the above.

However, the role of conflict in general and sustaining social identity is much less recognized. In other words, deep-rooted social identities can be as much the product of conflict as deeprooted conflicts are the product of confronted social identities. The blindness so widespread in this reverse process may be a group of the assumption that social identities are paramount, assumptions encoded in metaphors of blood and essence. This essentialism is a clear example of the contamination suffered by the press and the social sciences by biology and popular sociology, for example.

These blood or biological metaphors, as used by the press, the people, and the academy, permeate the ideology of social identity, especially that of race, nation, ethnicity, and language. These metaphors have the consequence of masking the culturally contingent bases of cultural identity under a veneer of naturalism precisely because its metaphorical status goes unnoticed. A good example of this way of thinking is represented by the comments made by Mohammad Khatami, President of the Islamic Republic of Iran, to 800 US residents refering as nationalism is a piece of land (...) and (he) is in your blood. Being true, then, that the two directions between identity and conflict exist, it is also true that identity by itself does not lead to conflict, in fact, some kind of identity is a necessary prerequisite for love, solidarity and altruism. It is a particular type of identity, the narcissistic identity, the one that leads to violent conflict. Narcissistic identities are generally based on some foundational myth that describes the group's noble or divine origins, and that it either celebrates past achievements or ancient injustices that impeded the group's development and wellbeing. 
A well-known characteristicelement, of those that we rescue, according to British author George Orwell ${ }^{1}$, to what he defines as a nationalist personality, or those signs that stand out as soon as we are faced with a nationalist sentiment, are:

a) The gathering of a feeling of defeat,

b) Find a common enemy, often responsible for this emotional defeat, which is to blame for all the ills of our society,

c) The rise of a national hero, often represented by the ideal citizen, the feeling of superiority before others, or a cartoon about the perfect person who represents us, of whom we are and to whom we should all aspire.

I invite you to all to find this on some particular moment of history known for being identified by "nationalistic". Narcissistic identity generates conflicts in at least four ways:

a. The founding myths are not falsifiable, and the disagreement with it, can not be approached neither with reason nor with persuasion. Here we rescue the inalienable and indisputable truth shared by the group, typical of the "groupthink".

b. These myths are by nature resistant to commitment.

c. Third, the positive self-image of the narcissistic group implies a negative vision of the other group. To be better, the other (or someone) must be worse.

d. Narcissistic identities overvalue themselves in such a way that they underestimate others, denying the ethical relevance of others.

When real or perceived conflicts of interest arise, real or perceived threats in relation to another group, the human, who as a rule abhors blood, reacts together with the group in ways that are totally outside the ethical standards that it maintains as an individual, without generally seeing any contradiction between being a good person and behaving as a fierce adversary in favor of the group (understood as a community, sect, ethnic group, nation state, etc.).

Relations between ethno-cultural minorities and majorities in non-homogeneous societies have always been difficult and often conflictive. Consequently, such conflicts have been characterized as "intractable" or "deep root", due to the psychological dimension that prevails over policies and economies. The problems between majority and minority communities that could be treated itherational plane, is complicated by the way in which ethnocultural groups perceive thelves and the "others" (out-group "), as the perception of their own history and the threats directed against their existence. This aspect of intergroup conflict has attracted great academic attention. In our opinion, the most relevant theory is the one that managed to introduce the concept of "Social identity theory"

H. Tajfel ${ }^{2}$, tries to explain, in five phases, social stratification, with a minority that accepts its inferior status, this is transformed into an unstable society, in which the majorities and minorities compete and conflict. Causal attribution and social comparison seem to be the psychosocial processes that play a fundamental role in this transition:

I. Strictly stratified intergroup relationships. The minority consider that they deserve their low status, which is due to their responsibility, the comparison they make minimizes their self-esteem, frequently leading them to hate themselves.

II. Emergence of individualistic social ideology. Minorities do not see the social structure as legitimate. The latter begins to make social comparisons based on individual abilities and merits, considering any stratification not referring to individual abilities as unacceptable. This change is the beginning of the intergroup conflict.

III. Social mobility. In this phase, those considered more gifted and skilled, those who are better educated, try to join the majority group. They try to assimilate totally or partially. They make social comparisons based on individual variables and develop strategies for themselves and their families, not for the entire group. Most tend to accept these assimilations, both because they demonstrate their superiority and because celebrating such assimilations produces a certain stability in society. The rest of the minority is pacified, therefore, with expectations, since, if they work hard, they can amount to assimilation.

IV. Increased awareness. Some of the highly qualified members of the minority fail, emotionally, to fully assimilate, or are rejected by the majority. Furthermore, the most disadvantaged of the minorities are aware that assimilation is impossible, thus beginning to raise group consciousness and claim that stratification must change, not at the individual level (since it has failed in them), but at the group level. Selfdeprecation is replaced by pride and ethnocentrism. Currently, the minority attributes the responsibility for their low status to discrimination by the dominant group.

V. Competitive intergroup relations. The increase in consciousness is followed by collective action: The minority

${ }^{1}$ Orwell, George (2018) “Notes on Natinalism” Penguin Books, London, United Kingdom

${ }^{2}$ Tajfel, H., \& Turner, J. C. (1979). "An integrative theory of intergroup conflict”. In W. G. Austin \& S. Worchel (eds.). The social psychology of intergroup relations.Monterey, CA: Brooks/Cole 
begins to fight against what it perceives as social injustice. Initially they argue that group division is illegitimate and obsolete. If these ideological arguments do not work, the conflict must remain at low levels, or on the contrary, escalate. If it is scale, the majority group may resort to violence and suppression, or it may decide to negotiate with the minority group to create mutually acceptable social norms.
Psychological factors are at the center of the motivating factor, although these, without losing their relevance, constitute only one aspect of conflicts based on social or group identities. These factors are related to others, as well as political, economic, historical, sociological, etc., thus, they reinforce those other factors and these are reinforced by them. Psychological perspectives must be fed back by those from other disciplines or sciences in a phenomenon as complex as the one proposed.

\section{(C) \\ This work is licensed under Creative Commons Attribution 4.0 License}

To Submit Your Article Click Here:

Submit Article

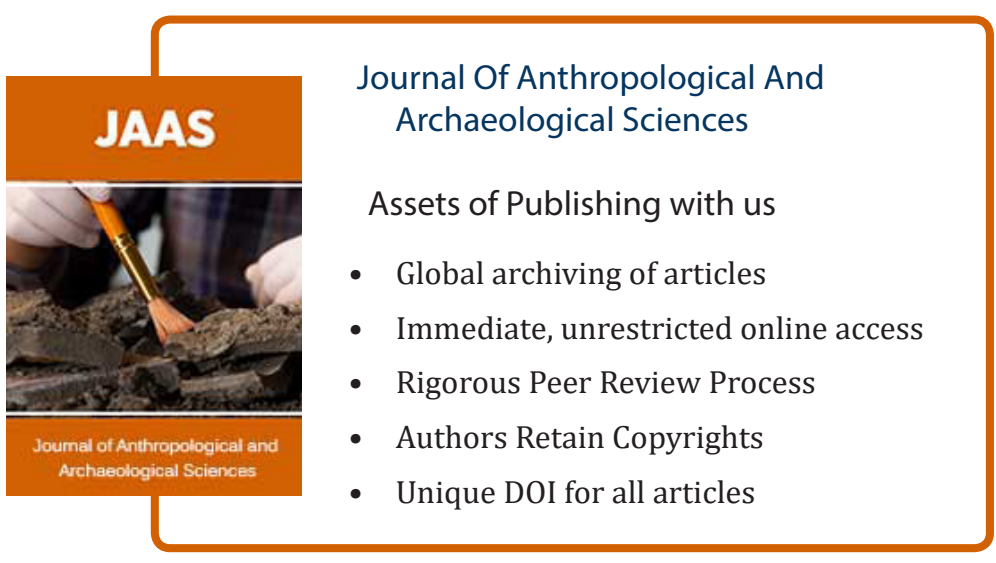

